\title{
Enhanced Survival and Mucosal Repair After Dextran Sodium Sulfate-Induced Colitis in Transgenic Mice That Overexpress Growth Hormone
}

\author{
KRISTEN L. WILLIAMS,* C. RANDALL FULLER, ${ }^{\ddagger}$ LEVINUS A. DIELEMAN, $\$, \|$ CHRIS M. DACOSTA, *,\| \\ KAAREN M. HALDEMAN,* R. BALFOUR SARTOR,§,\| and P. KAY LUND*,‡,\| \\ Departments of $*$ Cell and Molecular Physiology, ${ }^{*}$ Pediatrics, and \$Medicine, and llCenter for Gastrointestinal Biology and Disease, \\ University of North Carolina at Chapel Hill, Chapel Hill, North Carolina
}

Background \& Aims: Growth hormone (GH) is used as therapy for inflammatory bowel disease (IBD), but the specific effects on intestine are unknown. Transgenic mice overexpressing GH (MT1-bGH-TG) were used to test whether increased plasma GH levels alter inflammation or crypt damage during dextran sodium sulfate (DSS)induced colitis. Methods: MT1-bGH-TG and wild-type (WT) littermates were given $3 \%$ DSS for 5 days followed by up to 10 days of recovery. Colitis and epithelial cell proliferation were evaluated histologically. Plasma insulin-like growth factor (IGF)-I and colonic IGF-I, interleukin (IL)-1及, and intestinal trefoil factor (ITF) messenger RNAs (mRNAs) were measured. Results: DSS induced similar disease onset in MT1-bGH-TG and WT. More MT1-bGH-TG survived than WT. By recovery day 7, MT1bGH-TG had less inflammation and crypt damage, elevated plasma IGF-I, and increased colonic ITF expression relative to WT. Colonic IL-1 $\beta$ was elevated in DSStreated MT1-bGH-TG and WT, but IL-1 $\beta$ mRNA abundance correlated with disease only in WT. MT1-bGH-TG showed earlier increases in epithelial cell proliferation than WT during recovery but only WT showed atypical repair. Conclusions: GH does not alter susceptibility to acute DSS-induced colitis but enhances survival, remission of inflammation, and mucosal repair during recovery. GH therapy may be beneficial during active IBD by improving mucosal repair.

$\mathrm{U}$ lcerative colitis and Crohn's disease (CD) are chronic inflammatory diseases of the gastrointestinal tract. ${ }^{1,2}$ Malabsorption and weight loss are significant clinical problems in inflammatory bowel disease (IBD). ${ }^{3-5}$ Linear growth delay occurs in children with $\mathrm{IBD}^{4,5}$ and is associated with reduced levels of circulating insulin-like growth factor (IGF)-I. ${ }^{5}$ Bowel resection is a frequent complication of IBD that can further compromise nutritional status. ${ }^{6}$ In $\mathrm{CD}$, extensive resection of the small bowel leads to short bowel syndrome (SBS) in a small but clinically significant number of patients. ${ }^{6}$
There is increasing clinical interest in the use of trophic factors as therapy in patients with IBD or SBS because they may improve nutritional status, promote mucosal repair, and reduce the requirement for parenteral nutrition. ${ }^{7-12}$ In animal models, a number of growth factors seem to exert protective effects during intestinal inflammation, including intestinal trefoil factors $^{13}$ and transforming growth factor (TGF)- $\beta .{ }^{14}$ At present, recombinant human growth hormone (rhGH) is one of the few trophic factors in clinical use in patients with chronic IBD. Several clinical trials indicate benefits of $\mathrm{rhGH}$ therapy in adults with $\mathrm{SBS}^{7-11}$ including 2 placebo-controlled trials in patients with SBS caused by CD. ${ }^{10,11}$ Although each study reported that rhGH improved weight gain and lean body mass, there was no consensus about whether rhGH improved nutrient absorption. ${ }^{7-11}$ The 2 studies in CD patients were performed in patients with disease remission and therefore did not provide information about the effects of rhGH during ongoing intestinal inflammation and mucosal damage. A recent study reported decreased Crohn's Disease Activity Index, indicative of improvement in symptoms, in patients with active CD treated with rhGH. ${ }^{12}$ Although this indicates benefits of rhGH in patients with active $C D$, the specific actions of growth hormone $(\mathrm{GH})$ on the inflamed colon have not been elucidated. It seems likely that there will be additional therapeutic trials of rhGH in patients with IBD, so experimental evidence about the actions of $\mathrm{GH}$ on intestine during inflammation is desirable.

Abbreviations used in this paper: BrdU, 5'-bromodeoxyuridine; DSS dextran sodium sulfate; EGF, epidermal growth factor; IGF, insulin-like growth factor; ITF, intestinal trefoil factor; rhGH, recombinant human growth factor; SBS, short bowel syndrome; TGF, transforming growth factor; WT, wild-type.

(C) 2001 by the American Gastroenterological Association 0016-5085/01/ \$35.00 doi:10.1053/gast.2001.22470 
Most, if not all, prior studies of $\mathrm{GH}$ action on the bowel in animal models have focused on the small intestine. GH increased mass of small intestinal mucosa in hypophysectomized rats, ${ }^{15}$ in transgenic mice that have chronic GH excess caused by overexpression of bovine GH (MT1-bGH-TG), ${ }^{16}$ and in some ${ }^{17-19}$ but not all ${ }^{20}$ studies of animals with proximal small bowel resection. Little is known about the trophic effects of $\mathrm{GH}$ on the normal or inflamed colon, which is of particular relevance to the therapeutic effects of rhGH in IBD patients.

One theory of the pathogenesis of IBD is a defect in colonic healing, resulting in chronic intestinal inflammation. Oral administration of dextran sodium sulfate (DSS) induces acute colitis, followed by a relatively slow mucosal repair. ${ }^{21-23}$ This feature makes the DSS model useful for studying mechanisms of colonic wound healing and effects of therapeutic interventions on the healing process. Information about the recovery phase after DSS administration may be particularly relevant to development of therapies that could accelerate and promote mucosal repair in patients with active IBD. In the present study, we used MT1-bGH-TG and wild-type (WT) littermates to assess whether GH excess alters the development of and recovery from acute experimental colitis induced by DSS. Colon was examined for effects of $\mathrm{GH}$ on the severity or extent of inflammation as well as the amount of crypt damage. Colonic expression of the proinflammatory cytokine interleukin (IL)- $1 \beta$ was assessed because IL-1 $\beta$ expression is up-regulated during acute DSS-induced colitis and seems to be involved in disease severity. ${ }^{24-26}$

$\mathrm{GH}$ increases systemic IGF-I and also increases local IGF-I expression in the small intestine in some but not all situations. ${ }^{27,28}$ Effects of GH on colonic IGF-I expression have not been reported previously. Benefits of GH therapy in IBD or experimental models of colitis may be mediated wholly or in part by circulating or locally expressed IGF-I. We therefore examined plasma levels of IGF-I and colonic expression of IGF-I in DSS-treated MT1-bGH-TG and WT mice and water controls to determine if any effects of $\mathrm{GH}$ excess were associated with differences in circulating or locally expressed IGF-I. We also examined the expression of intestinal trefoil factor (ITF) and TGF- $\beta$ to determine whether any effects of $\mathrm{GH}$ were associated with altered expression of 2 known mediators of mucosal repair.

Trophic factors such as GH could promote mucosal healing by promoting proliferation of colonic epithelial cells, yet few studies have directly assessed crypt cell proliferation after inflammation-induced damage. IGF-I is a well-known proliferative factor for intestinal epithe- lial cells, ${ }^{29,30}$ but the effects of $\mathrm{GH}$ on crypt cell proliferation remain equivocal. Transgenic mice overexpressing GH show increased intestinal mass without concomitant increases in crypt cell mitosis. ${ }^{16}$ One year of $\mathrm{GH}$ replacement therapy in GH-deficient adults did not increase colonic crypt cell proliferation. ${ }^{31}$ In this study, we measured epithelial cell proliferation after DSS colitis using 5'-bromodeoxyuridine (BrdU) incorporation to establish whether MT1-bGH-TG mice show increased crypt cell proliferation during recovery from DSS-induced colitis.

\section{Materials and Methods}

\section{Transgenic Mice}

MT1-bGH-TG breeder pairs on a C57BL6/SJL genetic background were provided by Drs. Richard Palmiter, Ralph Brinster, and Richard Behringer. ${ }^{32}$ Hemizygous MT1bGH-TG males were mated with WT C57BL6/SJL females (Jackson Laboratories, Bar Harbor, ME) to provide MT1bGH-TG and WT littermates for the experiments. MT1bGH-TG mice are readily distinguished from WT by increased body weight, which is evident by postnatal day 28 . Genotype was verified on selected mice by polymerase chain reaction (PCR) on tail DNA using oligomers (sense, 5' - TTGACACAAACATGCGCAGT-3'; antisense, 5'-GCACTTCATGACCCTCAGGTAC- $3^{\prime}$ ) to the bovine GH gene, ${ }^{32}$ which revealed that genotyping by body weight was $100 \%$ reliable.

\section{Experimental Design}

DSS (mol wt, 34,000-45,000) was purchased from TDB Consultancy (Uppsala, Sweden). In pilot experiments, adult (55-75-day-old) sex-matched MT1-bGH-TG and WT littermates were given $4 \%$ or $3 \%$ (wt/vol) DSS in drinking water for 5 days and then switched to water and monitored for 10 additional days. With the $4 \%$ dose of DSS, mortality during the recovery phase was unacceptably high (see Results); thus 3\% DSS for 5 days was chosen as an optimal dose for detailed analyses. At least 6 age- and sex-matched MT1bGH-TG and WT mice were studied at the end of 5 days of 3\% DSS treatment (DSS) and at 3, 7, and 10 days after DSS (DSS + 3, DSS + 7, and DSS+10). Six control MT1-bGH-TG and WT littermate pairs were allowed free access to drinking water. Mice were housed individually in standard cages and were allowed to drink and feed ad libitum. Animals were weighed daily and stools were examined daily for blood (Hemoccult; SmithKline Diagnostics, San Jose, CA). All animal experiments were approved by the Institutional Animal Care and Use Committee of the University of North Carolina at Chapel Hill. Study protocols were in compliance with the Guide for the Care and Use of Laboratory Animals published by the National Institutes of Health. 


\section{Sample Collection}

Mice were anesthetized by an intramuscular injection of ketamine (900 $\mu \mathrm{g} / \mathrm{g}$ body wt; Parke Davis, Morris Plains, NJ) and xylazine (20 $\mu \mathrm{g} / \mathrm{g}$ body wt; Barber Veterinary Supply, Richmond, VA). Blood was collected by cardiac puncture, and plasma was separated by centrifugation. Plasma IGF-I concentrations were measured by radioimmunoassay after extraction on Sep-Pak C18 columns (Millipore, Bedford, MA) to remove IGF binding proteins, as described previously. ${ }^{33}$ The entire colon was dissected and contents flushed with ice-cold $0.9 \%$ saline. The distal third of the colon was dissected and split into three $0.5-\mathrm{cm}$ segments (D1, D2, and D3). D1 and D2 were fixed in $4 \%$ paraformaldehyde and Bouins fixative, respectively, and then embedded in paraffin to provide sections for histologic evaluation. ${ }^{24}$ The 2 different fixatives were used merely to facilitate future immunohistochemical studies. D3 was oriented in O.C.T. Compound (Tissue Tek, Torrance, CA) and frozen on dry ice and isopentane to provide frozen sections for in situ hybridization histochemistry and additional sections for histology. The remaining colon was homogenized immediately in $4 \mathrm{~mol} / \mathrm{L}$ guanidine thiocyanate, centrifuged to remove cell debris, then stored at $-80^{\circ} \mathrm{C}$ for extraction of total RNA. ${ }^{24}$ Mice were killed by exsanguination.

\section{Histologic Scoring of Inflammation and Crypt Damage}

The distal colon was evaluated because this is the most severely affected colonic segment in DSS-induced colitis. ${ }^{21,22}$ Sections from segments D1 and D3 were routinely scored. Sections from segment D2 were scored in a small subset of animals when the D1 or D3 sample showed poor morphology or to verify scores obtained on other sections. Previous pilot studies have established that evaluation of 2 or 3 segments of distal colon provides a reliable histologic score that reflects disease of the entire colon (P. Lund, unpublished observations, June 2000). Inflammation and crypt damage were assessed on H\&E-stained, coded sections using a modification of a validated scoring scheme described by Cooper ${ }^{22}$ and Dieleman ${ }^{23}$ as presented in Table 1 . Total colitis score is the sum of the 3 subscores (inflammation severity, inflammation extent, and crypt damage). Crypt hyperplasia has been noted during recovery from acute DSS-induced colitis and crypt dysplasia has been shown during chronic DSS-induced colitis. ${ }^{21}$ The possibility that GH may increase susceptibility to dysplasia is one potential concern in treating IBD patients with GH. ${ }^{10}$ We therefore scored the frequency of obvious crypt hyperplasia in MT1-bGH-TG or WT relative to controls and also noted the frequency of atypical epithelial healing, typified by bifurcated crypts, elevated lesions, and histologic disarrangement of epithelium. ${ }^{21,22}$ Histologic evaluation and scoring was performed using a Nikon MicrophotFXA microscope (Nikon, Garden City, NY) equipped with an Optronics DEI 750-3-chip (Optronics, Goleta, CA) CCD camera for digital imaging.
Table 1. Histologic Colitis Scoring Method

\begin{tabular}{ccl}
\hline Feature scored & Score & \multicolumn{1}{c}{ Description } \\
\hline Inflammation severity & 0 & None \\
& 1 & Mild \\
2 & Moderate \\
& 3 & Severe \\
Inflammation extent & 0 & None \\
& 1 & Mucosa \\
& 2 & Mucosa and submucosa \\
Crypt damage & 3 & Transmural \\
& 0 & None \\
& 1 & Basal 1/3 damaged \\
& 2 & Basal 2/3 damaged \\
& 3 & Crypts lost; surface epithelium \\
& & present \\
& 4 & Crypts and surface epithelium \\
Percent involvement & 0 & lost \\
& 1 & $1 \%-25 \%$ \\
& 2 & $26 \%-50 \%$ \\
& 3 & $51 \%-75 \%$ \\
& 4 & $75 \%-100 \%$ \\
\hline
\end{tabular}

\section{RNA Extraction and Northern Blot Hybridization Assays}

Extraction of total RNA and Northern blot hybridization assays of IGF-I, IL-1 $\beta$, and mouse ITF messenger RNAs (mRNAs) were performed as previously described. ${ }^{24}$ ${ }^{32} \mathrm{P}-U T P-l a b e l e d ~ m o u s e ~ I L-1 \beta,{ }^{24}$ rat IGF-I, ${ }^{24}$ or mouse ITF antisense RNAs were used as probes. The mouse ITF probe was kindly provided by Dr. Daniel Podolsky (Massachusetts General Hospital, Boston, MA). For TGF- $\beta 1$ Northern blots, a 327-base pair complementary DNA (cDNA) fragment generated by PCR using primers (antisense, 5'-GAGTGGTTATGATTTGATGT-3'; sense, 5'-GGTTCGTGAATCCATTTCCA-3'34) was labeled with ${ }^{32} \mathrm{P}-\mathrm{dCTP}$. Blots were reprobed with a mouse PL7 antisense RNA probe encoding a constitutively expressed ribosomal protein ${ }^{24}$ or with an antisense probe for the 28s ribosomal RNA (Ambion, Austin, TX), depending on whether the size of the control RNA could be readily distinguished from that of the test mRNA. Phosphoimager analyses quantified the hybridization signals. Abundance of IGF-I, IL- $1 \beta$, ITF, and TGF- $\beta 1$ mRNAs was normalized to the abundance of PL7 mRNA or 28s rRNA to control for minor differences in RNA loading. To normalize across multiple blots, values for IL-1 $\beta$, IGF-I, ITF, and TGF- $\beta 1$ mRNA abundance in each sample were expressed as a ratio of the mean value observed in WT water controls analyzed on the same blot.

\section{In Situ Hybridization Histochemistry}

IL-1 $\beta$ and IGF-I mRNAs were localized on frozen, $10-\mu \mathrm{m}$ cryostat sections of colon that were postfixed in $4 \%$ paraformaldehyde. In situ hybridization was performed using ${ }^{35}$ S-UTP-labeled antisense RNA probes as previously described. ${ }^{24,35}$ Sections were observed and photographed under light- and dark-field illumination using the Nikon 
Microphot-FXA microscope and digital imaging system. Sense RNA probes were used as specificity controls and gave uniformly negative signals (data not shown).

\section{BrdU Labeling of Proliferating Cells}

To assess colonic crypt cell proliferation, 2-3 pairs of MT1-bGH-TG and WT mice were treated with 3\% DSS for 5 days and injected with $6.4 \mathrm{mg} \operatorname{BrdU}$ (Sigma, St. Louis, MO) 90 minutes before being killed at DSS +3 , DSS +5 , or DSS +7 . Three pairs of water-treated control mice were also injected with BrdU. The colon was opened longitudinally and carefully rolled distal-to-proximal around a pipet tip, placed in an embedding cassette to maintain orientation, and then embedded in paraffin and sectioned. Immunohistochemistry was performed using an horseradish peroxidase-conjugated sheep anti-BrdU polyclonal antibody (Zymed, San Francisco, CA). Labeling index, the number of BrdU-positive cells per crypt, was assessed by a blinded observer. Only well-oriented, longitudinally sectioned crypts were counted. Twelve to 24 crypts were scored in each sample except in a small number of sections, in which the extent of ulceration was such that this was not possible.

\section{Reverse-Transcription PCR Analyses of TGF- $\alpha$, Epidermal Growth Factor, and TGF- $\beta$ 1-3}

cDNAs were generated from pooled RNA samples from mice of each genotype and treatment group using AMV Reverse Transcriptase (Promega, Madison, WI). Semiquantitative polymerase chain reaction was performed on each cDNA for mouse TGF- $\alpha$, epidermal growth factor (EGF), TGF- $\beta 1-3$, and glyceraldehyde-3-phosphate dehydrogenase using primers based on published sequences. Primers were as follows: TGF- $\alpha$, antisense, $5^{\prime}$-CCA CTG TCT ACA GTG GCA G-3', sense, 5'-CCT GTT AGC TGT GTG CCA GG-3'; EGF, antisense, 5'-CCA TCG TAG GTC TCG AGT C-3', sense, 5'-GCA ACT CCA CTC AGG CTG A-3'; TGF- $\beta 1-3$, antisense, 5'-GAG TGG TTA TGA TTT GAT GT-3', sense, 5'-GGT TCG TGA ATC CAT TTC CA-3'34; glyceraldehyde3-phosphate dehydrogenase, antisense, 5'-GCC ATG AGG TCC ACC ACC CTG TTG-3', sense primer, 5'-CTA CTG GCG CTG CCA AGG CTG T- $3^{\prime}$. The TGF- $\beta$ primers correspond to highly conserved regions in TGF- $\beta 1-3$, and therefore measures amplify all 3 TGF- $\beta$ isoforms.

\section{Statistical Analysis}

Values are expressed as mean \pm SE. Histologic scores and values for IL-1 $\beta$ or IGF-I mRNA abundance were analyzed by 1-way analysis of variance followed by pairwise comparisons using Tukey's test. Regression analyses were performed to test for correlations between histologic measures of disease and IL-1 $\beta$ or IGF-I mRNA abundance. A $P$ value $<0.05$ was considered statistically significant.

\section{Results}

\section{GH Excess Enhances Survival During DSS-Induced Colitis and Recovery}

All MT1-bGH-TG and WT mice survived 5 days of treatment with $4 \%$ DSS, but there was $25 \%$ mortality of MT1-bGH-TG mice and 50\% mortality of WT mice during the 10 days after cessation of $4 \%$ DSS. Therefore, this dose of DSS was not used further. With a $3 \%$ dose of DSS, $100 \%$ of MT1-bGH-TG and WT mice survived the 5-day treatment with DSS. During recovery, 100\% of MT1-bGH-TG (30 animals) survived the entire recovery phase, whereas 6 of 30 WT did not survive until the designated study time. MT1-bGH-TG mice consumed more DSS than their WT littermates during the 5 days of treatment $(44.75 \pm 2.10$ vs. $35.68 \pm 1.60 \mathrm{~mL}$; $P<0.05$ ), so enhanced survival in MT1-bGH-TG mice occurred despite consumption of more DSS than WT mice. Euthanasia was performed when necessary because of overt signs of serious disease (immobility and/or precipitous weight loss) in accordance with National Institutes of Health and institutional Institutional Animal Care and Use Committee guidelines regarding humane treatment of animals. In both the $4 \%$ and $3 \%$ DSS treatment protocols, death or need for euthanasia occurred between day 3 and 6 after DSS treatment.

\section{GH Excess Improves Overt Signs of Disease During Recovery Phase}

Percent loss of body weight and percent of animals that were Hemoccult positive were used as gross clinical indices of disease activity (Figure $1 A$ and $B$ ). Neither MT1-bGH-TG nor WT mice showed major loss of body weight during DSS treatment. During the recovery phase, the MT1-bGH-TG and WT mice that survived until the designated study time showed significant weight loss between day 2 and 5 after cessation of DSS (Figure $1 A$ ); mice began to gain weight by $5-6$ days after DSS treatment and had returned to their initial weight by recovery day 7 . In the animals that survived until the designated study time, neither the magnitude nor the time course of body weight loss differed significantly between MT1-bGH-TG and WT (Figure 1A). The WT mice that died or were killed during the recovery phase showed significantly greater weight loss consistent with more severe disease (Figure $1 A$ ). During DSS treatment, all but 1 MT1-bGH-TG and 1 WT mouse became Hemoccult positive between day 3 and 5 of treatment and there was no evidence for a difference in the time of disease onset between MT1-bGH-TG and WT, even though MT1-bGH-TG mice consumed a larger total amount of DSS. During the recovery phase, 

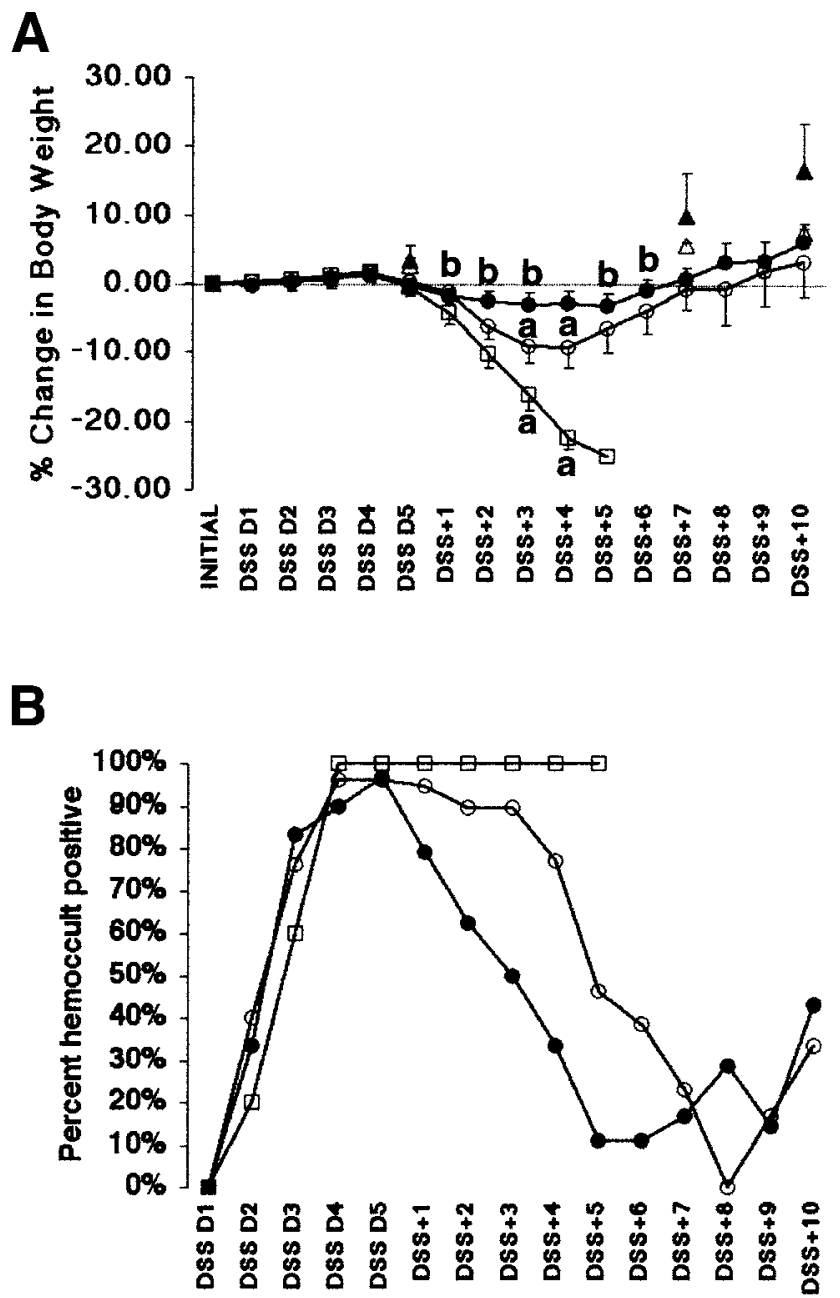

Figure 1. (A) Percentage body weight change during DSS treatment and recovery in MT1-bGH-TG $(-)$, WT that survived until the designated study time $(\bigcirc)$, and WT that did not survive until the intended study time ( $\square)$. Values are mean \pm SE of percentage body weight change in each animal relative to weight at the start of DSS treatment. Percentage body weight change in water-treated MT1-bGH-TG $(\mathbf{\Delta})$ and WT control $(\triangle)$ are shown for reference at DSS treatment day 5 , DSS +7 , and DSS+10. $n \geq 6$ animals at each time point except for WT that died or were killed. (B) Percentage of MT1-bGH-TG $(\mathbf{O})$, WT (O), or WT that did not survive recovery $(\square)$ that were Hemoccult positive on each day during DSS treatment and recovery. (A) $P<0.05$, DSS-treated WT mice vs. intial body weight. $(B) P<0.05$, DSS-treated MT1-bGH-TG mice vs. initial body weight. the percentage of Hemoccult-positive MT1-bGH-TG mice declined much more rapidly than WT. Those WT that died or were killed before the designated study time remained Hemoccult positive until death.

\section{GH Excess Reduces Inflammation and Mucosal Damage During Recovery From DSS-Induced Colitis}

Detailed analyses of histology and mRNA abundance and localization were performed only on those MT1-bGH-TG and WT mice treated with 3\% DSS that survived until the intended study time. By excluding from these analyses the most severely affected WT that died or were killed during recovery phase, the effects of $\mathrm{GH}$ on histologic and biochemical measures of disease were probably underestimated. Mean histologic scores for severity of inflammation, extent of inflammation, crypt damage, and total colitis are shown in Table 2. These scores did not differ significantly between MT1bGH-TG and WT littermates at the end of DSS treatment or at DSS+3. In both MT1-bGH-TG and WT mice, each parameter of the colitis score was higher at DSS +3 than at the end of DSS treatment, indicating that disease worsens in the period immediately after DSS treatment. In WT mice, inflammation, crypt damage, and total colitis scores showed no decline between 3 and 10 days after DSS administration. These scores were decreased in MT1-bGH-TG mice at DSS +7 and DSS +10 , and at these time points, each score was significantly lower in MT1-bGH-TG than in WT mice. Figure 2 shows H\&E-stained sections of the distal colon from representative MT1-bGH-TG and WT mice at different times after DSS to illustrate the similar inflammation/crypt damage at the end of DSS treatment and DSS +3 and the reduced inflammation and crypt damage in MT1-bGH-TG mice at DSS +7 and DSS+10. Obvious crypt hyperplasia was observed in a subset of MT1bGH-TG (44\%) and WT (51\%) mice during recovery from DSS-induced colitis (Figure 3). Atypical epithelial repair was observed in $32 \%$ of the WT analyzed during

Table 2. Histologic Scores of Severity or Extent of Inflammation, Crypt Damage, and Total Colitis

\begin{tabular}{llcccc}
\hline \multicolumn{1}{c}{ Score } & Type & DSS & DSS +3 & DSS +7 & DSS +10 \\
\hline Inflammation severity & TG & $4.6 \pm 0.8$ & $6.2 \pm 1.0$ & $3.7 \pm 0.5^{a}$ & $4.7 \pm 0.3^{a}$ \\
& WT & $4.1 \pm 0.9$ & $7.8 \pm 1.8$ & $7.5 \pm 1.3$ & $3.4 \pm 0.6^{a}$ \\
Inflammation extent & TG & $3.9 \pm 0.4$ & $6.6 \pm 0.7$ & $4.9^{a} \pm 0.5^{a}$ \\
& WT & $3.1 \pm 0.5$ & $6.3 \pm 1.3$ & $5.9 \pm 0.9$ & $7.2 \pm 1.3$ \\
Crypt damage & TG & $2.8 \pm 0.7$ & $4.5 \pm 1.2$ & $2.2 \pm 0.5^{a}$ & $2.3 \pm 0.4^{a}$ \\
Total colitis & WT & $2.7 \pm 0.7$ & $7.4 \pm 2.1$ & $6.3 \pm 1.8$ & $9.5 \pm 1.5$ \\
& TG & $11.2 \pm 1.7$ & $17.2 \pm 2.8$ & $9.3 \pm 1.4^{a}$ & $11.9 \pm 1.0^{a}$ \\
& WT & $10.0 \pm 2.1$ & $21.5 \pm 5.2$ & $19.6 \pm 4.0$ & $21.6 \pm 3.8$ \\
\hline
\end{tabular}

aP $<0.05$ MT1-bGH-TG vs. WT mice in the same treatment group. $\mathrm{n}=6$ or 7 animals in each treatment group. Scores reflect evaluation of $2-3$ segments of distal colon for each animal. 

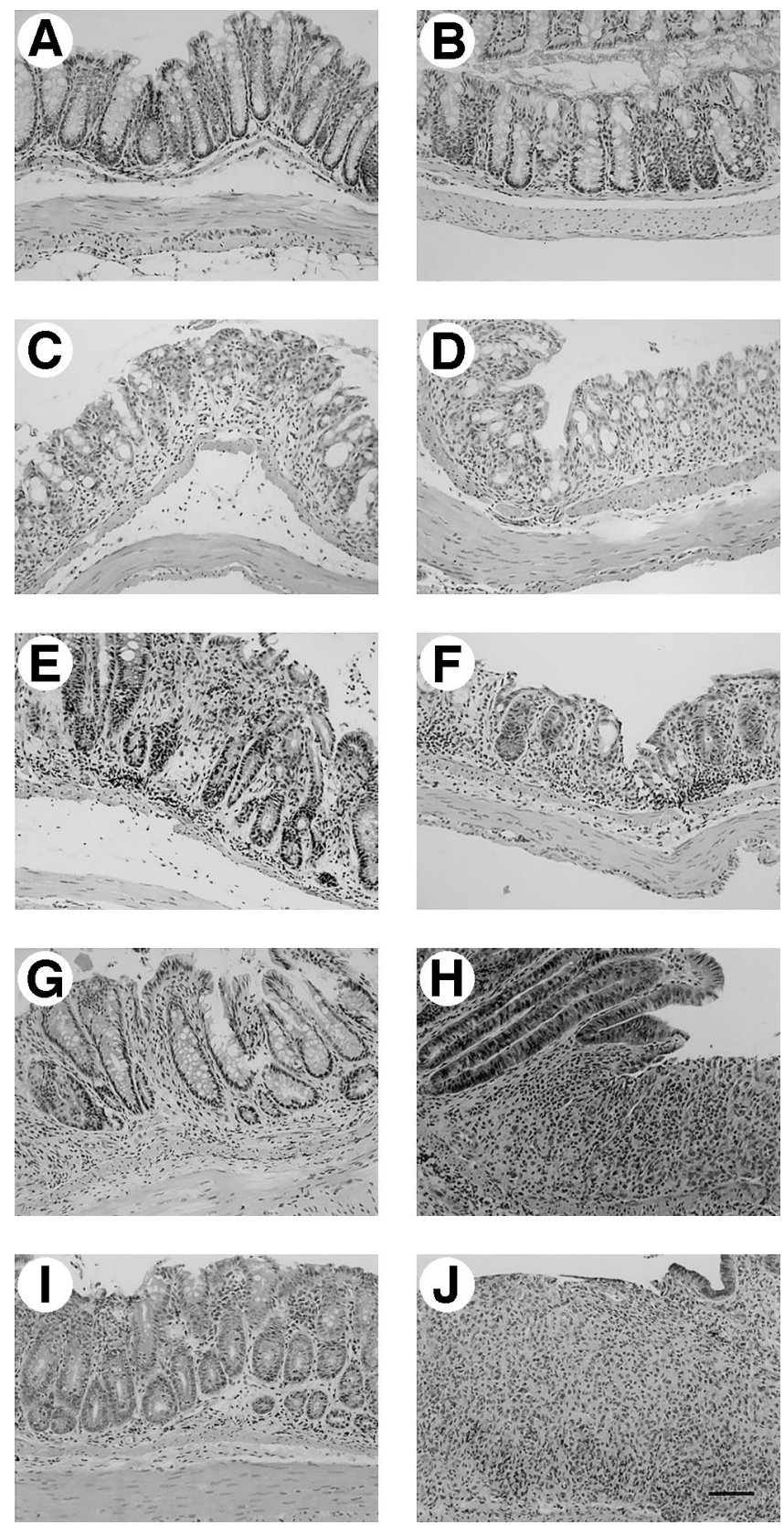

Figure 2. Representative photomicrographs of H\&E-stained sections of distal colon from ( $A, C, E, G$, and $I)$ MT1-bGH-TG and $(B, D, F, H$, and $J)$ WT mice. ( $A$ and $B$ ) Control mice; $(C$ and $D)$ end of DSS treatment; $(E$ and $F)$ DSS +3 ; $(G$ and $H)$ DSS $+7 ;(I$ and $J) \mathrm{DSS}+10 . B a r=100$ $\mu \mathrm{m}$ in all sections.

the recovery phase but in no MT1-bGH-TG mice. Figure 3 shows examples of the atypical epithelial repair observed in WT.

\section{Expression of Colonic IL-1及 mRNA Is Increased in Both MT1-bGH-TG and WT}

IL-1 $\beta$ mRNA expression was assayed as a biochemical marker of inflammation. Figure $4 A$ and $B$ shows representative Northern blots of IL- $1 \beta$ mRNA
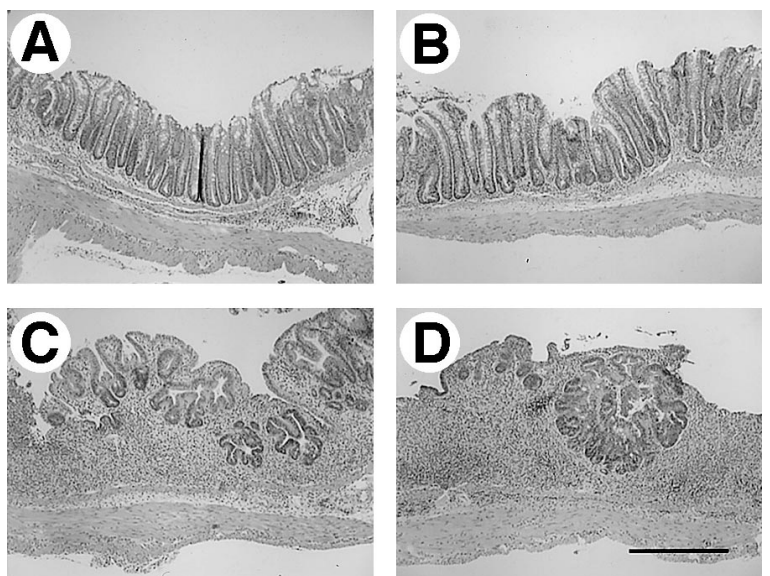

Figure 3. H\&E-stained sections of colon during recovery phase show crypt hyperplasia in $(A)$ MT1-bGH-TG and $(B)$ WT mice and $(C$ and $D)$ atypical mucosal repair observed only in WT mice. Bar $=500 \mu \mathrm{m}$ in all sections.

and the mean IL-1 $\beta$ mRNA abundance in control and DSS-treated MT1-bGH-TG and WT mice. DSS treatment significantly elevated IL-1 $\beta$ mRNA in both MT1bGH-TG and WT mice, but there was considerable variability in the absolute levels of IL-1 $\beta$ mRNA among

A

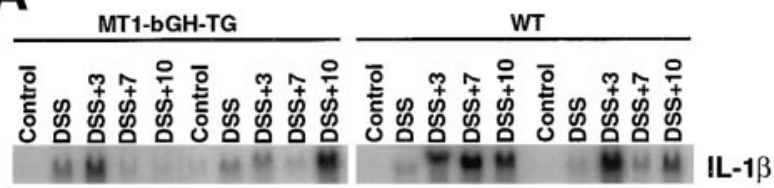

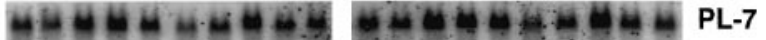

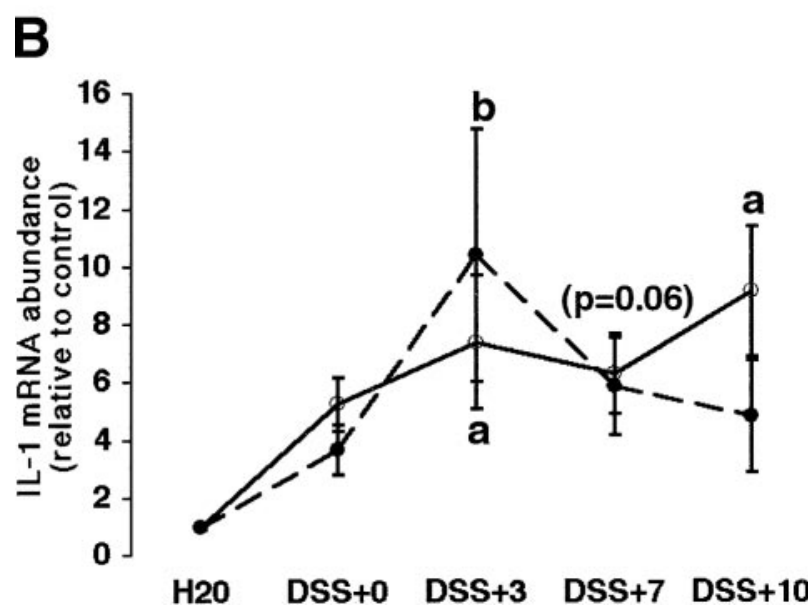

Figure 4. (A) Representative Northern blots show IL-1 $\beta$ and control PL7 mRNA expression in colon of MT1-bGH-TG and WT mice. Water controls and time points after DSS treatment are indicated. $(B)$ Mean IL-1 $\beta$ abundance in MT1-bGH-TG $(\bullet)$ and WT $(\bigcirc)$ mice. Values are mean \pm SE of fold difference relative to the mean value in WT water controls analyzed on the same blots. $n \geq 6$ per condition or time point. ${ }^{a} P<0.05$ DSS-treated WT vs. WT control; ${ }^{b} P<0.05$ DSStreated MT1-bGH-TG vs. MT1-bGH-TG control. 
animals and in the time course of IL- $1 \beta$ mRNA induction (Figure $4 A$ ). Mean IL-1 $\beta$ mRNA abundance did not differ significantly between MT1-bGH-TG and WT at the end of DSS treatment or at any time point after DSS treatment. Regression analyses revealed that the abundance of IL-1 $\beta$ mRNA in individual DSS-treated MT1bGH-TG showed no significant correlation with any colitis score (severity of inflammation, $r=0.27, P=$ 0.23; extent of inflammation, $r=0.39, P=0.07$; crypt damage, $r=0.03, P=0.89$; and total colitis, $r=0.24$, $P=0.29)$. In DSS-treated WT mice, there were highly significant correlations between IL-1 $\beta$ mRNA abundance and severity of inflammation $(r=0.64, P<$ $0.001)$, extent of inflammation $(r=0.67, P<0.001)$, crypt damage $(r=0.66, P<0.001)$, and total colitis $(r=0.67, P<0.001)$. In situ hybridization revealed similar sites of colonic IL-1 $\beta$ mRNA expression in MT1-bGH-TG and WT mice. Data are shown for WT in Figure 5. At the end of DSS treatment, IL-1 $\beta$ was observed primarily in scattered cells within the lamina propria. During the recovery phase, IL- $1 \beta$ was more strongly and more widely expressed in the lamina propria and in addition was observed in the muscularis propria.

\section{Plasma Levels of IGF-I and Colonic Expression of IGF-I During DSS Colitis and Recovery}

Because IGF-I is a major mediator of GH action, plasma IGF-I and local IGF-I expression were measured to assess whether differences in IGF-I were associated with effects of GH. Plasma levels of IGF-I were significantly elevated in MT1-bGH-TG water controls relative to control WT mice and were significantly greater in DSS-treated MT1-bGH-TG than in WT mice at the end of DSS treatment and at DSS +7 and DSS +10 (Table 3). The latter time points correspond to times when improved mucosal repair was observed in MT1-bGH-TG mice. In WT mice, DSS treatment did not significantly alter plasma IGF-I levels relative to water controls. In MT1-bGH-TG mice, plasma IGF-I levels were significantly lower than in water controls at DSS+3, DSS +7, and DSS +10 . Values in MT1-bGH-TG were lowest at DSS +3 when plasma IGF-I did not differ significantly from WT. Colonic levels of IGF-I mRNA expression were modestly increased in both MT1-bGH-TG and WT mice at the end of DSS treatment relative to water controls (Figure 6). IGF-I mRNA tended to remain slightly elevated throughout the recovery phase, although this did not achieve statistical significance because of variability among animals. There was no
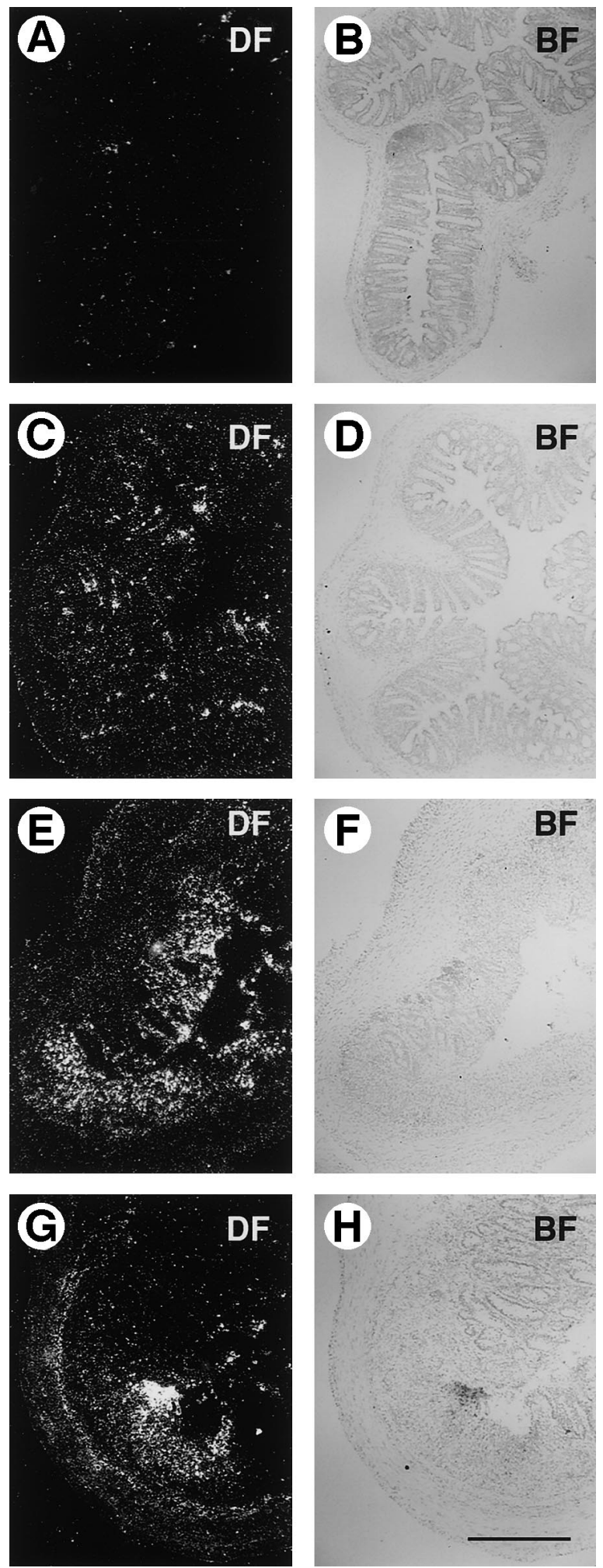

Figure 5. Dark-field (DF) and bright-field (BF) photomicrographs of sections of distal colon from control or DSS-treated WT mice hybridized with an IL-1 $\beta$ antisense RNA probe. ( $A$ and $B$ ) Control; $(C$ and $D$ ) end of DSS; $(E$ and $F)$ DSS +3 ; $(G$ and $H)$ DSS +7 . Bar $=500 \mu \mathrm{m}$. 
Table 3. Plasma IGF-I Concentrations $(\mathrm{ng} / \mathrm{mL})$

\begin{tabular}{lccccc}
\hline & $\mathrm{H}_{2} \mathrm{O}$ & DSS & DSS +3 & DSS +7 & DSS +10 \\
\hline TG & $1509 \pm 92^{a}$ & $1700 \pm 133^{a}$ & $742 \pm 131^{b}$ & $1130 \pm 54^{a, b}$ & $1148 \pm 40^{a, b}$ \\
WT & $571 \pm 46$ & $690 \pm 65$ & $676 \pm 242$ & $490 \pm 62$ & $502 \pm 43$ \\
\hline
\end{tabular}

NOTE. Values are mean \pm SE for $6-10$ animals per time point. ${ }^{a} P<0.05$ in MT1-bGH-TG vs. WT mice in the same treatment group.

${ }^{b P}<0.05$ in DSS-treated MT1-bGH-TG mice vs. water-treated MT1-bGH-TG controls.

significant difference in mean IGF-I abundance in colon of water or DSS-treated MT1-bGH-TG relative to WT mice (Figure 6). IGF-I mRNA was localized in colon at selected time points. Hybridization signals for IGF-I tended to be low, and data are shown in Figure 7 for those WT that exhibited convincing hybridization signals. Localization patterns were similar in MT1-bGH-TG mice (data not shown). IGF-I mRNA was expressed in the lamina propria and muscularis propria. Immune cell aggregates that were observed in the mucosa during DSS-induced colitis
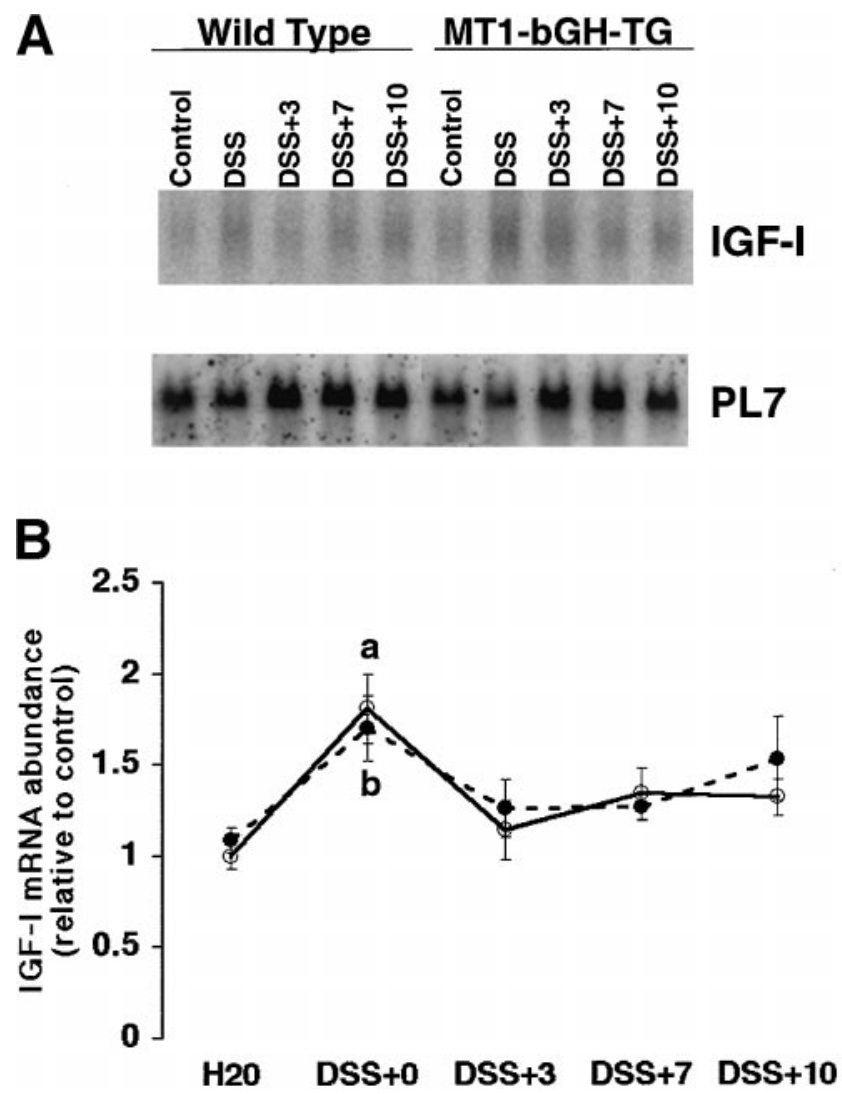

Figure 6. (A) Representative Northern blots showing IGF-I and control (PL7) mRNA expression in the colons of MT1-bGH-TG and WT mice. Water controls and treatments are indicated. $(B)$ Mean IGF-I mRNA abundance in DSS-treated MT1-bGH-TG $(\bullet)$ and WT $(\bigcirc)$ mice. Values are the mean $\pm S E$ of the fold difference relative to the mean value of WT water controls analyzed on the same blot. $\mathrm{n} \geq 6$ for each group. a $P<0.05$ DSS WT vs. WT control; ${ }^{b} P<0.05$ DSS-treated MT1bGH-TG vs. MT1-bGH-TG controls. were negative for IGF-I mRNA (Figure $7 G$ and $H$ ). Hybridization signals revealed by in situ hybridization tended to be higher for IGF-I mRNA during the recovery phase even though Northern blot hybridization data did not reveal significant increases in IGF-I mRNA. This may reflect proportionate increases in IGF-I mRNA and increases in the relative mass of cells expressing other, more abundant mRNAs.

\section{Improved Mucosal Repair in MT1-bGH-TG Is Associated With Increased Crypt Cell Proliferation}

Because improved mucosal healing was evident in MT1-bGH-TG mice by DSS + 7 but not at DSS +3, follow-up studies were performed in which BrdU was administered to a separate group of DSS-treated MT1-bGH-TG and WT mice at DSS+3, DSS+5, and DSS+7 to assess whether increased crypt cell proliferation could account for the effects of GH. DSS +5 was included in this follow-up study because we reasoned that elevated crypt cell proliferation may precede the first time point when improved mucosal repair was evident in MT1-bGH-TG mice. Water controls injected with BrdU were analyzed in parallel. As shown in Table 4, the number of BrdU-positive cells per crypt did not differ significantly in control MT1-bGH-TG and WT mice. However, both MT1-bGH-TG and WT showed increases in crypt cell proliferation during recovery from DSS colitis, consistent with crypt regeneration as a component of mucosal repair. Increased crypt cell proliferation was observed earlier in MT1-bGH-TG mice; numbers of BrdU-positive cells per crypt were higher in MT1bGH-TG than in WT mice at DSS +3 and DSS +5 . These time points precede the improved mucosal repair in MT1bGH-TG at DSS+7. In WT mice, significant increases in numbers of BrdU-positive cells relative to WT water controls were not observed until DSS +7 , indicating slower crypt regeneration in WT than in MT1-bGH-TG.

\section{Improved Mucosal Repair in MT1-bGH-TG Reflects Increased Expression of ITF but not TGF- $\beta 1-3$, EGF, or TGF- $\alpha$}

Expression of ITF and TGF- $\beta 1$, molecules implicated in mediating mucosal repair, was assessed by 

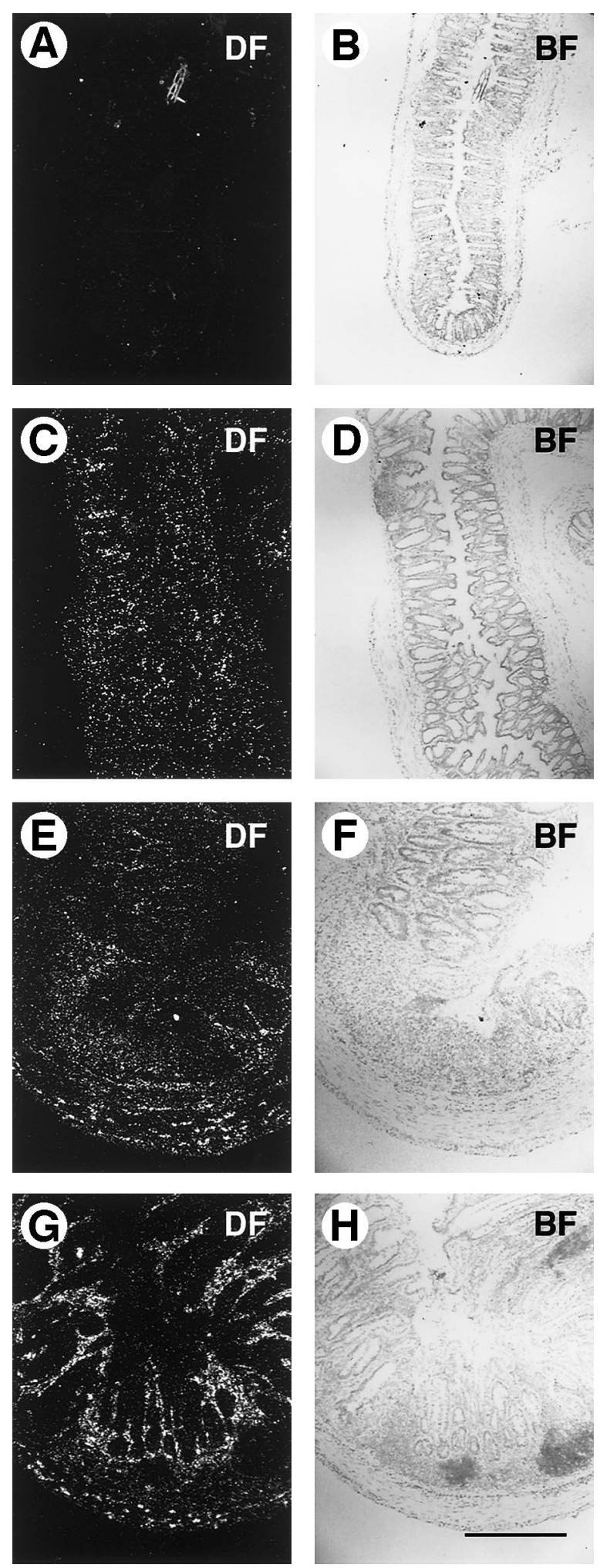

Figure 7. Dark-field (DF) and corresponding bright-field (BF) photomicrographs of the distal colon of WT mice hybridized with IGF-I antisense RNA probe. ( $A$ and $B$ ) Control; $(C$ and $D$ ) end of DSS; $(E$ and $F$ ) DSS $+7 ;(G$ and $H) D S S+10$. All sections are shown at the same magnification. Bar $=500 \mu \mathrm{m}$.
Table 4. BrdU Labeling Index in DSS-Treated MT1-bGH-TG and WT Mice

\begin{tabular}{lllll}
\hline & $\mathrm{H}_{2} \mathrm{O}$ & \multicolumn{1}{c}{$\mathrm{DSS}+3$} & $\mathrm{DSS}+5$ & $\mathrm{DSS}+7$ \\
\hline $\mathrm{TG}$ & $3.6 \pm 0.2$ & $8.4 \pm 0.9^{a, b}$ & $5.5 \pm 0.6^{b}$ & $4.9 \pm 0.3^{b}$ \\
WT & $2.9 \pm 0.2$ & $4.2 \pm 0.9$ & $4.7 \pm 0.8$ & $6.8 \pm 0.4^{c}$ \\
\hline
\end{tabular}

NOTE. Values are means \pm SEM for the number of BrdU-positive cells per crypt counted. $\mathrm{n}=13-65$ crypts in 2-3 animals per treatment group. The variation in number of crypts counted reflects the fact that WT had fewer intact crypts than MT1-bGH-TG.

a $P<0.05$ for MT1-bGH-TG vs. WT in the same treatment group.

${ }^{b} P<0.05$ for DSS-treated MT1-bGH-TG vs. control MT1-bGH-TG mice. ${ }^{c} P<0.05$ for DSS-treated WT vs. control WT mice.

Northern blot in MT1-bGH-TG and WT mice. These analyses were performed on 2 separate samples of pooled RNA from 3 animals per genotype and treatment group because of limited availability of RNA. Northern hybridization of ITF mRNA revealed a modest increase in steady-state mRNA abundance in control MT1bGH-TG relative to control WT mice (Figure 8). ITF mRNA expression was also increased in MT1-bGH-TG relative to WT at DSS+3 and DSS+7 (Figure 8). No major differences in TGF- $\beta 1$ mRNA abundance were detected between MT1-bGH-TG and WT mice at any time point (data not shown). EGF, TGF- $\alpha$, and TGF及2-3 mRNAs were assessed by reverse-transcription polymerase chain reaction. These analyses revealed low expression of EGF, TGF- $\alpha$, TGF- $\beta 2$, and TGF- $\beta 3$ mRNA, which showed no major induction at any time after DSS and no evidence for significant differences between MT1-bGH-TG and WT mice (data not shown).

\section{Discussion}

This study shows that chronic elevation of plasma GH did not have a significant protective effect on the onset or severity of acute colitis induced by DSS or associated mucosal damage. GH excess did, however, improve survival during recovery from colitis, promote remission of inflammation, and enhance mucosal repair. The more precipitous weight loss in the WT mice that did not survive the recovery period compared with MT1bGH-TG supports the concept that anabolic effects of $\mathrm{GH}$ to maintain body weight contributed to the enhanced survival of MT1-bGH-TG. Histologic evidence of enhanced remission of inflammation and mucosal damage as well as improved disease remission were observed in MT1-bGH-TG, which showed a similar percentage loss in body weight as WT that survived recovery phase. These data indicate that $\mathrm{GH}$ excess improves recovery from colitis by specific effects on the colon.

Any proposed mechanism for the protective effects of $\mathrm{GH}$ must take into account the fact that DSS treatment 
A
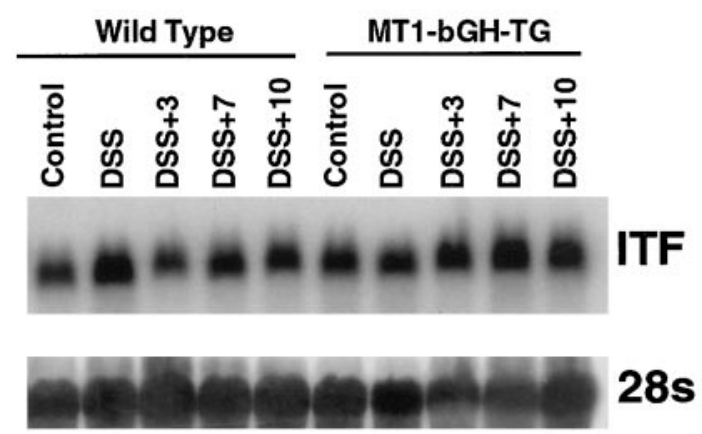

B

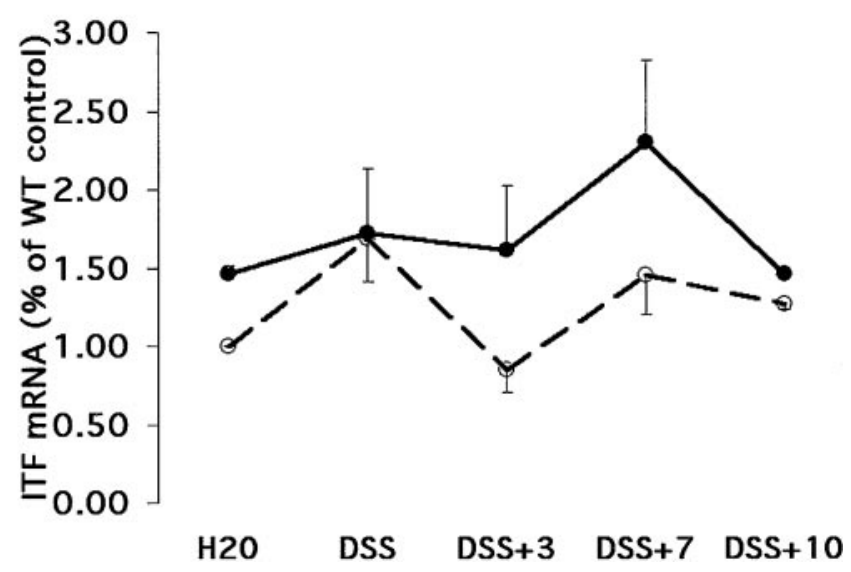

Figure 8. (A) Representative Northern blot showing ITF mRNA and control 28S ribosomal RNA expression in pooled samples from MT1bGH-TG and WT mice. Water-treated controls and treatment times are indicated. ( $B$ ) Mean ITF mRNA abundance in DSS-treated MT1-bGH-TG $(\bigcirc)$ and WT $(\bigcirc)$ mice. Values are the means \pm SEM of the fold differences relative to the values for WT water controls. Where error bars are not shown, they are smaller than the size of the symbol. $n=$ 2 pooled samples of total RNA from 3 animals per treatment group.

induced similar inflammation and crypt damage in MT1bGH-TG and WT and that MT1-bGH-TG showed reduced inflammation and crypt damage only during recovery from DSS. At the end of DSS treatment and during the recovery phase, there were similar increases in colonic IL-1 $\beta$ mRNA in MT1-bGH-TG and WT mice, indicating that $\mathrm{GH}$ excess does not significantly alter the induction of this proinflammatory cytokine. IL-1 $\beta$ mRNA abundance showed a strong correlation with inflammation, crypt damage, and total colitis in WT but not MT1-bGH-TG mice, raising the intriguing possibility that GH may inhibit the bioactivity of IL-1 $\beta$ induced during intestinal inflammation; this possibility warrants future investigation.

Crypt regeneration is an important component of mucosal healing after acute inflammation and mucosal damage. ${ }^{23,36}$ BrdU labeling data indicate that both MT1bGH-TG and WT mice show increased crypt cell proliferation during recovery from DSS-induced colitis. The more rapid increase in crypt cell proliferation in MT1-bGH-TG than in WT mice provides evidence that GH may improve or accelerate mucosal repair by effects on crypt cell proliferation. This effect of GH seemed to be transient because maximum increases in crypt cell proliferation occurred at 3 days after DSS treatment, before evidence of mucosal repair, and then declined toward levels in water controls.

The transient effect of GH on crypt cell proliferation rate is relevant to potential risks and benefits of $\mathrm{GH}$ therapy during active IBD. As patients with IBD have an increased risk of colorectal cancer, it would in fact be desirable that therapy with trophic factors accelerate mucosal repair and crypt regeneration without prolonged effects to increase crypt cell proliferation. Our data indicate that this may be a characteristic of $\mathrm{GH}$ action. In addition, our data provide no evidence that $\mathrm{GH}$ excess causes atypical epithelial repair. Bifurcated crypts, elevated lesions, and histologic disarrangement of the epithelium were observed in a significant number of WT mice but in no MT1-bGH-TG mice. Thus, at least after acute mucosal damage associated with colitis, our findings provide no evidence that even dramatic $\mathrm{GH}$ excess causes aberrant epithelial repair. In this regard, it is noteworthy that multiple cycles of DSS cause chronic colitis associated with crypt dysplasia. ${ }^{21}$ It will therefore be of interest to evaluate if $\mathrm{GH}$ excess alters the frequency of crypt dysplasia or neoplasia during chronic DSS-induced colitis. Reduced crypt cell apoptosis represents another potential mechanism by which GH could promote musocal healing. At present, there is little or no information about the role of apoptosis in mucosal healing after colitis. However, a recent study in rats given abdominal radiation showed that GH reduced radiationinduced apoptosis of ileal epithelial cells, although not to the same extent as IGF-I. ${ }^{37}$ This is clearly a potentially interesting avenue of future investigation that is relevant to the possible risks and benefits of GH therapy in IBD.

A major consideration is whether effects of $\mathrm{GH}$ to promote mucosal healing or accelerated crypt cell proliferation reflect direct actions of $\mathrm{GH}$ or indirect actions mediated by other growth factors or known mediators of mucosal repair. We assessed circulating and locally expressed IGF-I because IGF-I is a major mediator of GH action ${ }^{27}$ and crypt epithelial cells are known targets for IGF-I action. ${ }^{27,29,30}$ Plasma IGF-I levels were elevated in DSS-treated MT1-bGH-TG mice relative to WT at the end of DSS treatment and at DSS +7 and DSS +10 , times when improved mucosal repair was evident. It is therefore possible that endocrine actions of IGF-I contribute 
to improved mucosal healing in MT1-bGH-TG mice. It is noteworthy, however, that the elevated plasma IGF-I in MT1-bGH-TG at the end of DSS treatment was not associated with any reduction in mucosal inflammation or damage, indicating that neither GH nor IGF-I can protect against mucosal damage. Furthermore, there was not a direct temporal correlation between plasma IGF-I levels and effects of GH to accelerate crypt cell proliferation and mucosal repair. At DSS +3 , a time associated with maximal crypt cell proliferation in MT1-bGH-TG, plasma IGF-I levels were actually lower than in water controls and were not significantly different than in WT. This decline in plasma IGF-I in MT1-bGH-TG is intriguing because it suggests that the early phase of recovery from DSS-induced colitis may be associated with an uncoupling of the ability of excess $\mathrm{GH}$ to increase circulating IGF-I. It is established that proinflammatory cytokines such as IL-1 $\beta$ can inhibit the action of GH to induce synthesis of IGF-I in the liver, the major source of circulating IGF-I. ${ }^{38,39}$ If plasma IL-1 $\beta$ were elevated during DSS colitis, this could inhibit the GH-induced production of IGF-I in the liver. The findings about plasma IGF-I in MT1-bGH-TG mice therefore do not exclude an endocrine role of circulating IGF-I as a contributor to the enhanced mucosal healing in MT1-bGH-TG mice, but they do not indicate a strict correlation between the effects of $\mathrm{GH}$ on mucosal healing and plasma IGF-I.

Colonic expression of IGF-I was elevated in DSStreated MT1-bGH-TG and WT mice, consistent with our previous observations in WT mice given DSS, ${ }^{24}$ other rodent models of intestinal inflammation, ${ }^{35,40}$ and patients with CD. ${ }^{41}$ The similar levels of local IGF-I expression in DSS-treated MT1-bGH-TG and WT mice suggest that local IGF-I expression is not increased by circulating $\mathrm{GH}$ during acute colitis or during recovery and probably does not contribute to the improved mucosal repair in MT1-bGH-TG mice. Our prior studies showed modest increases in local IGF-I expression in the small intestine of normal MT1-bGH-TG mice. ${ }^{16}$ Our current data in water and DSS-treated MT1-bGH-TG mice indicate that the colon is less responsive to actions of $\mathrm{GH}$ in terms of induction of local IGF-I expression. Colonic IGF-I was expressed primarily in the lamina propria and muscularis propria during DSS colitis and was not obviously expressed in immune cell aggregates. These findings suggest that IGF-I is expressed in mesenchymal cells during DSS-induced colitis, as we have observed in other animal models of inflammation. ${ }^{35,40}$ Locally expressed, mesenchymal cell-derived IGF-I may contribute to wound healing responses during intestinal inflammation, ${ }^{27}$ but it does not seem to mediate improved mucosal healing in MT1-bGH-TG mice.

Because we observed no evidence that locally expressed IGF-I correlates with improved mucosal healing, we assessed whether expression of other molecules that mediate mucosal healing or regeneration was altered in MT1-bGH-TG mice. Our studies indicate that expression of ITF is slightly higher in control MT1-bGH-TG mice than in WT. This may reflect increased mass of the colonic mucosa and increased numbers of goblet cells, which are sources of ITF. ${ }^{13,42}$ The higher level of ITF mRNA in MT1-bGH-TG mice at DSS+3 represents a time when MT1-bGH-TG show similar crypt damage as WT and so is probably not simply a reflection of increased number of goblet cells. This evidence indicates that GH excess may induce ITF expression and that ITF may contribute to the beneficial effects of $\mathrm{GH}$ on mucosal healing. Other known mediators of wound healing, such as EGF, TGF- $\alpha$, and TGF- $\beta 1-3$, were not found to be elevated in control or DSS-treated MT1-bGH-TG versus WT mice, and thus are not likely mediators of the effects of GH to promote healing after DSS treatment.

In conclusion, our findings in MT1-bGH-TG mice indicate beneficial effects of $\mathrm{GH}$ to promote mucosal repair and remission of inflammation after acute DSSinduced colitis by effects that include accelerated but transient increases in crypt cell proliferation and no evidence for atypical mucosal repair. These data add to a growing body of evidence suggesting beneficial effects of rhGH in patients with $\mathrm{CD}^{10-12}$ and indicate that some effects of GH may be mediated by elevated circulating IGF-I and colonic ITF expression.

\section{References}

1. Fiocchi C. Inflammatory bowel disease: etiology and pathogenesis. Gastroenterology 1998;115:182-205.

2. Sartor RB. Current concepts of the etiology and pathogenesis of ulcerative colitis and Crohn's disease. Gastroenterol Clin North Am 1995;24:475-507.

3. Dieleman LA, Heizer WD. Nutritional issues in inflammatory bowe disease. Gastroenterol Clin North Am 1998;27:435-451.

4. Savage MO, Beattie RM, Camacho-Hubner C, Walker-Smith JA, Sanderson IR. Growth in Crohn's disease. Acta Paediatr 1999; 88:89-92.

5. Kirschner BS, Sutton MM. Somatomedin-C: levels in growth-impaired children and adolescents with chronic inflammatory bowel disease. Gastroenterology 1986;91:830-836.

6. Becker JM. Surgical therapy for ulcerative colitis and Crohn's disease. Gastroenterol Clin North Am 1999;28:371-390.

7. Byrne TA, Persinger RL, Young LS, Ziegler TR, Wilmore DW. A new treatment for patients with short-bowel syndrome. Growth hormone, glutamine, and a modified diet. Ann Surg 1995;222:243254.

8. Sax HC. New treatment for patients with short-bowel syndrome: growth hormone, glutamine and a modified diet. JPEN J Parenter Enteral Nutr 1996;20:375-376.

9. Wilmore DW, Lacey JM, Soultanakis RP, Bosch RL, Byrne TA. 
Factors predicting a successful outcome after pharmacologic bowel compensation. Ann Surg 1997;226:288-292.

10. Ellegard L, Bosaeus I, Nordgren S, Bengtsson BA. Low-dose recombinant human growth hormone increases body weight and lean body mass in patients with short bowel syndrome. Ann Surg 1997;225:88-96.

11. Scolapio JS, Camilleri M, Fleming CR, Oenning LV, Burton DD, Sebo TJ, Batts KP, Kelly DG. Effect of growth hormone, glutamine, and diet on adaptation in short-bowel syndrome: a randomized, controlled study. Gastroenterology 1997;113:10741081.

12. Slonim AE, Bulone L, Damore MB, Goldberg T, Wingertzahn MA, McKinley MJ. A preliminary study of growth hormone therapy for Crohn's disease. N Engl J Med 2000;342:1633-1637.

13. Mashimo H, Wu DC, Podolsky DK, Fishman MC. Impaired defense of intestinal mucosa in mice lacking intestinal trefoil factor. Science 1996;274:262-265.

14. Kulkarni AB, Huh CG, Becker D, Geiser A, Lyght M, Flanders KC, Roberts AB, Sporn MB, Ward JM, Karlsson S. Transforming growth factor $\beta 1$ null mutation in mice causes excessive inflammatory response and early death. Proc Natl Acad Sci U S A 1993:90:770-774.

15. Taylor B, Murphy GM, Dowling RH. Pituitary hormones and the small bowel: effect of hypophysectomy on intestinal adaptation to small bowel resection in the rat. Eur J Clin Invest 1979;9:115127.

16. Ulshen $\mathrm{MH}$, Dowling RH, Fuller CR, Zimmermann E, Lund PK. Enhanced growth of small bowel in transgenic mice overexpressing bovine growth hormone. Gastroenterology 1993;104;973980.

17. Waitzberg DL, Cukier C, Mucerino DR, Logulo AF, Torrinhas RS, de Castro I. Small bowel adaptation with growth hormone and glutamine after massive resection of rat's small bowel. Nutr Hosp 1999;14:81-90.

18. Shulman DI, Hu CS, Duckett G, Lavallee-Grey M. Effects of short-term growth hormone therapy in rats undergoing $75 \%$ small intestinal resection. J Pediatr Gastroenterol Nutr 1992; 14:3-19.

19. Iannoli P, Miller JH, Ryan CK, Gu LH, Ziegler TR, Sax HC. Human growth hormone induces system $B$ transport in short bowel syndrome. J Surg Res 1997;69:150-158.

20. Vanderhoof JA, Kollman KA, Griffin S, Adrian TE. Growth hormone and glutamine do not stimulate intestinal adaptation following massive small bowel resection in the rat. J Pediatr Gastroenterol Nutr 1997;25:327-331.

21. Okayasu I, Hatakeyama S, Yamada M, Ohkusa T, Inagaki Y, Nakaya R. A novel method in the induction of reliable experimental acute and chronic ulcerative colitis in mice. Gastroenterology 1990;98:694-702.

22. Cooper HS, Murthy SNS, Shah RS, Sedergran DJ. Clinicopathologic study of dextran sulfate sodium experimental murine colitis. Lab Invest 1993;69:238-249.

23. Dieleman LA, Palmen MJHJ, Akol H, Bloemena E, Pena AS, Meuwissen SGM, Van Rees EP. Chronic experimental colitis induced by dextran sulphate sodium (DSS) is characterized by Th1 and Th2 cytokines. Clin Exp Immunol 1998;114:385391.

24. Savendahl L, Underwood LE, Haldeman KM, Ulshen MH, Lund PK. Fasting prevents experimental murine colitis produced by dextran sulfate sodium and decreases interleukin-1-beta and insulin-like growth factor I messenger ribonucleic acid. Endocrinology 1997;138:734-740.

25. Arai $\mathrm{Y}$, Takanashi $\mathrm{H}$, Kitagawa $\mathrm{H}$, Okayasu I. Involvement of interleukin-1 in the development of ulcerative colitis induced by dextran sulfate sodium in mice. Cytokine 1998;10:890-896.

26. Elson CO, Cony Y, Brandwein S, Weaver CT, McCabe RP, Mahler M, Sundberg JP, Leiter EH. Experimental models to study molec- ular mechanisms underlying intestinal inflammation. Ann $\mathrm{N} \mathrm{Y}$ Acad Sci 1998;3859:85-95.

27. Lund PK. IGFs and the digestive tract. The insulin-like growth factors system. In: Roberts CT, Rosenfeld R, eds. The IGF system. Totowa, NJ: Humana, 1999:517-544.

28. Yang H, Ney DM, Peterson CA, Lo H-C, Carey HV, Adamo ML. Stimulation of intestinal growth is associated with increased insulin-like growth factor-binding protein 5 mRNA in the jejunal mucosa of insulin-like growth factor-I treated parenterally fed rats. Proc Soc Exp Biol Med 1997;216:438-445.

29. Ohneda K, Ulshen MH, Fuller CR, D'Ercole AJ, Lund PK. Enhanced growth of small bowel in transgenic mice expressing human insulin-like growth factor I. Gastroenterology 1997;112: 444-454.

30. Simmons JG, Hoyt EC, Westwick JK, Brenner DA, Pucilowska JB, Lund PK. Insulin-like growth factor-I and epidermal growth factor interact to regulate growth and gene expression in IEC-6 intestinal epithelial cells. Mol Endocrinol 1995;9:1157-1165.

31. Beentjes JS, van Gorkom BA, Sluiter WJ, de Vries EG, Kleibeuker $\mathrm{JH}$, Dullaart RP. One year growth hormone replacement therapy does not alter colonic epithelial cell proliferation in growth hormone deficient adults. Clin Endocrinol 2000;52:457-462.

32. Mathews LS, Hammer RE, Brinster RL, Palmiter RL. Expression of insulin-like growth factor I in transgenic mice with elevated levels of growth hormone is correlated with growth. Endocrinology 1988;123:433-437.

33. Underwood LE. Clinical uses of IGF-I and IGF binding protein assays. In: Roberts CT, Rosenfeld R, eds. The IGF system. Totowa, NJ: Humana, 1999:617-632.

34. Frank S, Madlener M, Werner S. Transforming growth factors $\beta 1$, $\beta 2$, and $\beta 3$ and their receptors are differentially regulated during normal and impaired wound healing. J Biol Chem 1996;271: 10188-10193.

35. Zimmermann EM, Sartor RB, McCall RD, Pardo M, Bender D, Lund PK. Insulin-like growth factor-I and interleukin 1 beta messenger RNA in a rat model of granulomatous enterocolitis and hepatitis. Gastroenterology 1993;105:399-409.

36. Tessner TG, Cohn SM, Schloemann S, Stenson WF. Prostaglandins prevent decreased epithelial cell proliferation associated with dextran sodium sulfate injury in mice. Gastroenterology 1998:115:874-882.

37. Mylonas PG, Matsouka PT, Papandoniou EV, Vagianos C, Kalfarentzos F, Alexandrides TK. Growth hormone and insulin-like growth factor I protect intestinal cells from radiation induced apoptosis. Mol Cell Endocrinol 2000;160:115-122.

38. Thissen JP, Verniers J. Inhibition by interleukin-1 beta and tumor necrosis factor-alpha of the insulin-like growth factor I messenger ribonucleic acid response to growth hormone in rat hepatocyte primary culture. Endocrinology 1997;138:1078-1084.

39. Wolf M, Bohm S, Brand M, Kreymann G. Proinflammatory cytokines interleukin 1 beta and tumor necrosis factor alpha inhibit growth hormone stimulation of insulin-like growth factor I synthesis and growth hormone receptor mRNA levels in cultured rat liver cells. Eur J Endocrinol 1996;135:729-737.

40. Zhee JM, Mohapatra N, Lund PK, Eysselein VE, McRoberts JA Differential expression and localization of IGF-I and IGF binding proteins in inflamed rat colon. J Recept Signal Transduct Res 1998;18:265-280.

41. Pucilowska JB, Mohapatra NK, McNaughton KK, Hoyt EC, Zimmermann EM, Sartor RB, Lund PK. IGF-I and procollagen1(I) are co-expressed in a subset of mesenchymal cells in active Crohn's disease. Am J Physiol 2000;279:G1307-G1322.

42. Podolsky DK. Mucosol immunity and inflammation. V. Innate mechanisms of mucosal defense and repair: the best offense is a good defense. Am J Physiol 1999;277:G495-G499. 
Received March 23, 2000. Accepted November 9, 2000.

Address requests for reprints to: Kristen L. Williams, B.S., Department of Cell and Molecular Physiology, University of North Carolina at Chapel Hill, Chapel Hill, North Carolina 27599-7545. e-mail: klwms@med.unc.edu; fax: (919) 966-6927.

Supported by a predoctoral fellowship from the Howard Hughes Medical Foundation (to K.L.W.), a grant from the Crohn's and Colitis Foundation of America, and National Institutes of Health grant
DK47709 (to P.K.L. and R.B.S.). The study was facilitated by the molecular histopathology core of the Center for Gastrointestinal Biology and Disease (NIH P30-DK-34987) and mouse pathology, tissue culture, and DNA synthesis cores of the Lineberger Cancer Center (NIH CA16086).

The authors thank Dr. John Woosley for assistance with pathology, Eileen Hoyt for assistance with image analyses, Evonne Bruton for assistance with radioimmunoassays, Kirk McNaughton for assistance with histology, and Deborah Carver for secretarial assistance. 